\title{
Announcing the winner of the 2009 Kurt Jellinger Prize
}

\author{
Werner Paulus
}

Published online: 18 July 2009

(C) Springer-Verlag 2009

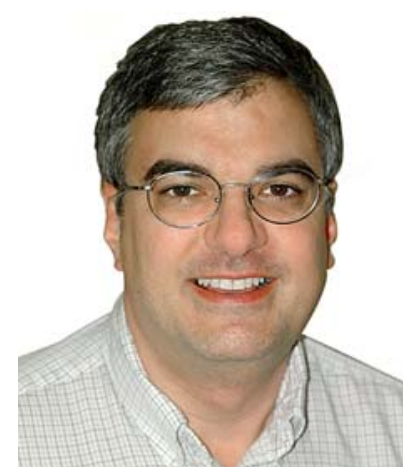

The winner of this year's Kurt Jellinger Prize for Excellence in Scientific Writing is Dr. Norman L. Lehman. The prize winning review paper, entitled "The ubiquitin proteasome system in neuropathology" is included in this issue of the journal. The ubiquitin proteasome system is involved in the pathogenesis of most neuropathologies, and Dr. Lehman's topical paper describes and illustrates its central role for brain tumors, neurodegeneration, cognitive disorders, and muscle and nerve diseases. The paper reflects the author's expertise in both neurobiology and neuropathology.
Dr. Lehman earned M.D. and Ph.D. degrees from the University of Southern California in 1994 and 1998, respectively. His graduate research was focused on the molecular pharmacology of antifolate chemotherapy drugs. Following a residency in anatomic and clinical pathology at Creighton University from 1997 to 2000, he moved to Stanford University, where he served as neuropathology fellow, postdoctoral research fellow and staff neuropathologist. Dr. Lehman's interest in the ubiquitin proteasome system began at Stanford where he studied cell cycle regulation by the anaphase promoting complex inhibitor Emil and its ability to generate genomic instability and promote tumorigenesis when overexpressed. In 2007, he moved to Henry Ford Hospital, Detroit, MI, where he is currently the Chief of the Division of Neuropathology and Co-Director of the Electron Microscopy Laboratory. Dr. Lehman's NIH-funded research focusses on the role of components and substrates of the ubiquitin proteasome system in brain tumors, such as Emi1, Cdh1, aurora A and securin, which may also have implications for other pathologies including neurodegeneration.

The prize includes invitations to deliver the Kurt Jellinger Lecture and to join the Editorial Board of Acta Neuropathologica. Congratulations and welcome aboard!
W. Paulus $(\bowtie)$

Institute of Neuropathology, University Hospital Münster,

Domagkstr. 19, 48129 Münster, Germany

e-mail: werner.paulus@uni-muenster.de 